\title{
Feasibility Study of Cardboard Waste Recycling
}

\author{
Mahdi Esmieo*, Moad Shaklawon, Omar Shaneb \\ Department of Industrial engineering, College of Industrial Technology - misurata, Libya \\ DOI: https://doi.org/10.21467/proceedings.4.38 \\ * Corresponding author email: mahdi.esmieo@gmail.com
}

\begin{abstract}
Waste management and utilization strategies are major concerns in several countries. Cardboard recycling is a common technique for treating Paper waste, as production recipe contains waste mass by $80 \%$, printed paper contains toxic substances that are used in the manufacture of inks and colors, and their disposal by incineration produces toxic fumes as well as carbon in the form of small grains attached to the air and attack the human respiratory system. In most developed countries where land is scarce and the environmental controls are strict, environmental policies tend to reduce landfill disposals as much as possible. In this paper a feasibility study of cardboard waste recycling in Misurata has been conducted. The paper explores the technical options available for a such recycling. Determine the factors that are considered important for the economic success of the project. In addition, a feasibility study has been conducted. Several economic indicators such as payback period, internal rate of return have been estimated. The results have shown that cardboard recycling is economically feasible. Furthermore, a sensitivity analysis for the important factors have been conducted in order to show their effect on the feasibility that system.
\end{abstract}

Keywords: Cardboard, economic, recycling, feasibility study, waste.

\section{Introduction}

Rapid expansion of industry, urbanization and increasing of population, especially in large cities like Misurata, has dramatically increased the amount of solid waste generated in Libya. However, issues related to sound municipal solid waste management - including waste reduction and disposal - have not been addressed adequately. In addition, the collection and the separation treatment of solid waste are still neglected. In the last few years, the Environmental General Authority in Libya has worked to create regulations and instructions for waste management, but up to now they are still under development [6]. This belongs to the fact that there is only little information available regarding recycling, handling and disposal of waste. Therefore, an appraisal of the current situation regarding solid waste management in Libya is required [1]. Cardboard recycling is a common practice of solid waste management in European countries, for it renders the economic success of the project. On the contrary, most

(C) 2018 Copyright held by the author(s). Published by AIJR Publisher in Proceedings of First Conference for Engineering

Sciences and Technology (CEST-2018), September 25-27, 2018, vol. 2 .
This is an open access article under Creative Commons Attribution-NonCommercial 4.0 International (CC BY-NC 4.0)

AiR license, which permits any non-commercial use, distribution, adaptation, and reproduction in any medium, as long as the original work is properly cited. ISBN: 978-81-936820-6-7 
Feasibility Study of Cardboard Waste Recycling

of the solid waste in Libya is still dumped. Municipal solid waste contains valuable cardboard that could be recycled.

Solid waste management and cardboard waste recycling (CWR) have attracted significant attention and great deal of research in several countries such as Denmark [8], America [7], Australia [4], South Africa [5], and India [2]. Rare studies on solid waste have been conducted in Libya indicating that no proper management is existing yet [3,6]. Thus, work is still required to establish a database, information and statistics on CWR, collection, transportation and treatment. In this paper, economic indicators was investigated and its factors that are considered important for the economic success of the project was determined.

\section{Cardboard Recycling.}

Cardboard is one of the most commonly used materials for packaging and comes in a variety of forms. Also referred to as corrugated cardboard. It is a recyclable material that could be recycled by cardboard factories to save money. It is a recyclable material that could be recycled by cardboard factories to save money Instead of being disposed as landfill or burn them. Cardboard recycling is the reprocessing and reuse of thick sheets or stiff multi-layered papers that have been used, discarded or regarded as waste. Products that are made from recycled cardboard include more cardboard boxes, egg cartons and even kitty litter.

\section{Study area}

Misurata is the third largest city in Libya. It serves a community of about 400,000 people. The study has been conducted in the city of Misurata, which situated in the western north part of Libya as a case study. In this paper, CWR feasibility study in the city of Misurata has been investigated through an extensive survey contained information on collection, internal transport and treatment.

\subsection{Waste collection, transportation and final treatment}

Solid wastes generated at all zones are collected by municipal companies, and then transported to the final dumping site. There are three trans-shipment points in the city. The municipality has the responsibility for offsite transportation of the waste to the final disposal site. From daily to three times a week [6], the municipality labor collect the solid wastes from the on-site storage containers and transport them along with general domestic waste to open dumping sites outside the city. Generally, simple trucks and in some cases uncovered tractors are used for waste transportation [6]. These open tractors are passing within residential areas which increases the potential risk to the public and the environment. All domestic waste dispose, are in open dumping sites outside of the city [6]. In these open dumping sites, the waste is buried and sometimes combusted. Figure 1 shows the quantity of $\mathrm{CW}$ in one of the zones.

ISBN: 978-81-936820-6-7

705

Series: AIJR Proceedings

Proceedings DOI: $10.21467 /$ proceedings.4 


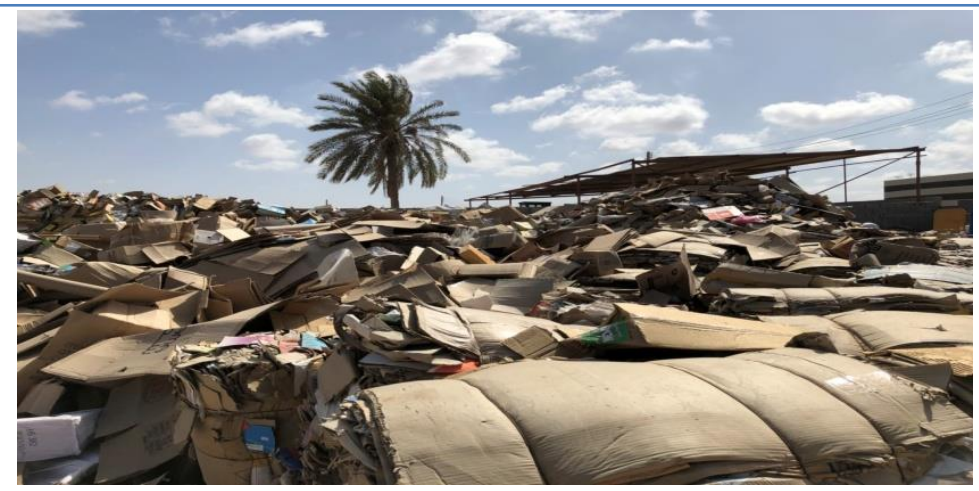

Figure 2 depicts the qualitative analysis of solid waste in Misurata identifies organics as the major component $(56 \%)$, followed by plastics $(26.5 \%)$. This high plastic rate is due to the widespread use of disposables rather than the reusable for different purposes (e.g. bottles, packing materials and food bags). Whereas paper had the third highest percentage (8\%) [6].

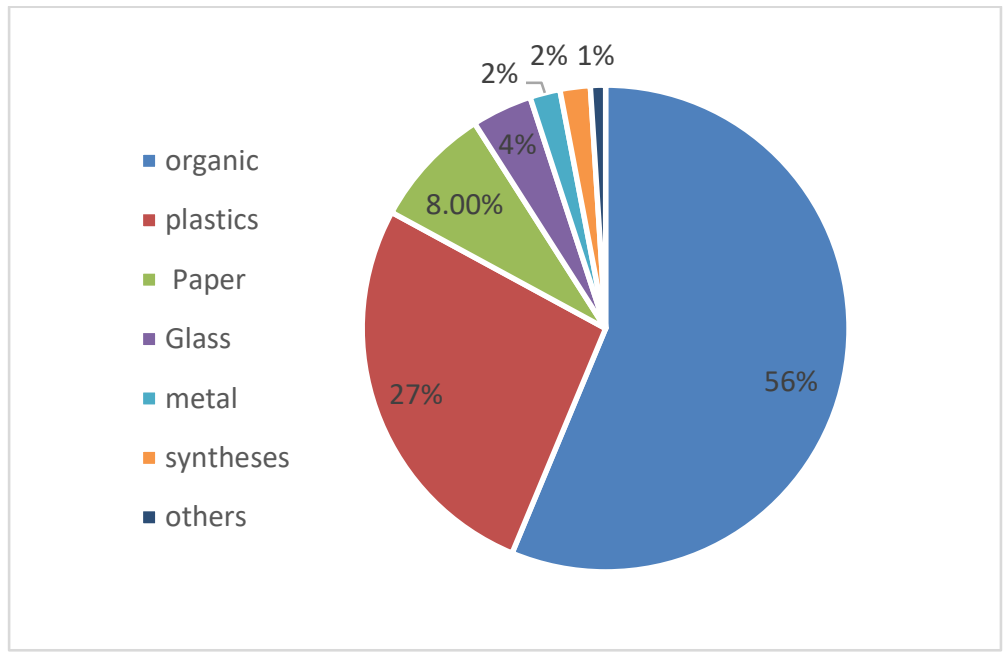

\section{$4 \quad$ Feasibility Study}

The present study was conducted through various field visits to several areas within the city of Misurata as well as cardboard factories in the city. This study is concerned with the feasibility study of establishing a CR plant to produce egg dishes. The assumed plant capacity is 20 ton per month to produce 250,000 dishes (i.e. 1200 dishes per hour).

\subsection{Raw materials}

The raw material used in the recycling of cardboard depends heavily on the waste of paper and cardboard by up to $80 \%$. To produce one ton of carton roll, the following quantities and materials shown in table 1 are required: This industry needs a large amounts of water for the 
Feasibility Study of Cardboard Waste Recycling

cleaning and forming process, and then the paper is re-dried until the percentage of water reaches only $6 \%$, which is the percentage allowed in the carton. Thus, the weight of the egg dish is $80 \mathrm{~g}$.

\begin{tabular}{|l|l|}
\hline Material description & $\%$ \\
\hline $\begin{array}{l}\text { Corrugated Cardboard } \\
\text { (Mixed Cardboard) }\end{array}$ & $80 \%$ \\
\hline paper-making additives (pulp) & $18 \%$ \\
\hline Chemicals \& reagents & $0.2 \%$ \\
\hline Abiatic acid & $1.8 \%$ \\
\hline
\end{tabular}

\subsection{Cardboard Recycling Process}

The cardboard recycling process involves a number of steps, including collection, transportation, sorting, processing into usable raw materials and finally using that raw material to produce new egg dishes products. At the reprocessing plant, cardboard and water are mixed together at high speed in a 'Turboflex Pulp Maker' to break up the cardboard into separate fibres. Contaminants such as staples, wires, plastics and strings are removed by passing the pulp through a cleaning and screening equipment. The pulp is then treated with chemicals and heated to loosen ink and glue so they can be washed out. The cleaned pulp is diluted with water and mixed with small amounts of paper-making additives. The paper is then turned into new Egg dishes products, using the same pressing and drying process used to make paper and cardboard from virgin materials.

In the refining stage, the pulp is beaten to make the paper fibers swell. In this process, egg dishes are obtained. When the goal is to produce white recycled paper, the pulp is bleached with oxygen or chlorine dioxide to make them brighter or whiter or coloring using other artificial colors.

\subsection{Costs}

\subsubsection{Materials Cost}

Table 2 shows the first year total materials cost. The total cost equals to the summation of materials fee aaccording to annual production capacity.

\begin{tabular}{|l|c|c|c|}
\hline Material description & Quantity & $\begin{array}{c}\text { Unit Cost, } \\
\$\end{array}$ & $\begin{array}{c}\text { Contribution, } \\
\$ / 20 \text { ton }\end{array}$ \\
\hline Mixed Cardboard & 16 ton & 70 & 1120 \\
\hline paper-making additives (pulp) & $3.6 \mathrm{ton}$ & 272 & 979.2 \\
\hline Chemicals \& reagents & $40 \mathrm{~kg}$ & 0.83 & 33.2 \\
\hline Abiatic acid & $0.360 \mathrm{ton}$ & 363 & 130.68 \\
\hline Grand total per year & \multicolumn{3}{|l}{} \\
\hline
\end{tabular}




\subsubsection{Assumptions}

- Recycling equipment's \& installation cost $=99,000 \$$.

- Waste input to incinerator $=75 \%$ of the total waste.

- $\quad$ Depreciation rate $=5 \%$.

- The yearly operational cost of the recycling plant includes utility costs water $28,500 \$$ at a rate of $44 \mathrm{~m}^{3}$ per month, electricity 12,000 Kw monthly, human resource costs shown in table 3 , and other administrative costs, excluding equipment maintenance cost equal to $40,000 \$$.

- The average population growth (for the last 30 years) equal to $2 \%$ [9].

\begin{tabular}{|l|l|l|l|l|}
\hline \multicolumn{1}{|c|}{ job description } & \multicolumn{1}{|c|}{ Job Requirements } & \multicolumn{1}{c|}{ number } & Salary \$ & Total salary \$ \\
\hline Production Manager & project management & 1 & 1500 & 1500 \\
\hline Production Supervisor & Supervision and control & 1 & 1100 & 1100 \\
\hline Labor operation & Production \& processing & 5 & 800 & 4000 \\
\hline Grand total per & \multicolumn{4}{|l}{$6600 /$ month } \\
\hline
\end{tabular}

\section{Calculation and Results}

The indices calculated are the yearly profit, net present value, and break-even point. Tables 4 and (5) explain the calculations for the first year. Table 2 illustrates the total quantity of waste collected each year.

Table 4: Waste generated

\begin{tabular}{|l|l|}
\hline \multicolumn{2}{|c|}{ Possible waste per year } \\
\hline Cardboard waste per year & 1500 \\
\hline Waste incinerated (75\% ) & 1125 \\
\hline$\bullet \quad$ Ability & $8 \mathrm{hr} /$ day \\
\hline Time & $1200 \mathrm{pc} / \mathrm{hr}$ \\
\hline Capacity line & $3,000,000 \mathrm{pc} /$ year \\
\hline Capacity & \\
\hline
\end{tabular}

Table 5 shows the first year total revenue. The total revenue equals to the summation of egg dishes selling revenue. The average price for dish equal to $0.30 \$$.

Table 5: shows the first year total revenue

\begin{tabular}{|r|r|r|}
\hline & Description & Quantity \\
\hline \multicolumn{3}{|c|}{ Fosts } \\
\hline \multicolumn{4}{|c|}{ Fixed Costs } & $36,000 \$$ \\
\hline Variable Costs & Operational Costs & $427,800 \$$ \\
\hline
\end{tabular}

Proceedings of First Conference for Engineering Sciences and Technology (CEST-2018), vol. 2 708 
Feasibility Study of Cardboard Waste Recycling

\begin{tabular}{|r|r|}
\hline \hline Maintenance & $40,000 \$$ \\
\hline Raw materials & $27,156.9 \$$ \\
\hline Total Variable costs & $494,956 \$$ \\
\hline Total costs & $530,956 \$$ \\
\hline Revenue & $3,000,000 * 0.30$ \\
\hline Egg dishes (average price $=0.30 \$)$ & $900,000 \$$ \\
\hline Total Revenue & $306,190.1$ \\
\hline Net Profit &
\end{tabular}

Whereas: Contribution $=$ unit price- unit variable cost.

Breakeven point $=$ Fixed cost $/$ contribution

- Breakeven point $=\frac{36000}{0.30-0.20}=360,000$

Figure (3) depicts the yearly profit of the plant. It is clear that the project loses only during the first 2 years under the given conditions.

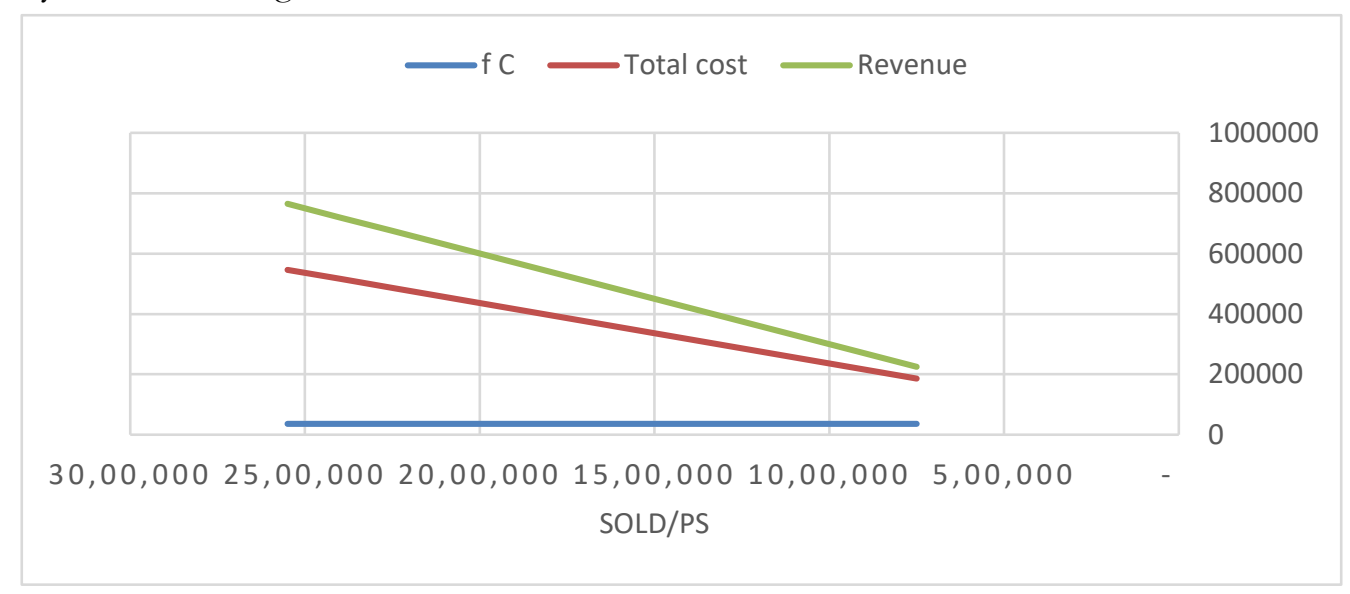

\section{Conclusions}

In light of the increasing importance for environmentally waste recycling while maintaining the proper stewardship of pollution and solid waste, CWR plants have the ability to become a vital part of the Libya industry. The result of the cost analysis indicates potential economic savings for the Recycling system in Misrata. It is suggested that a similar study should be undertaken focusing on other waste types so as to further underpin future waste management objectives in Libya.

\section{References}

[1] A. Omran, A.Gebril, A. Pakir, Municipal Solid Waste Management in BENGHAZI (LIBYA): Current Practices and Challenges, Environmental Engineering and Management Journal, Vol.9, No. 9, 1289-1296, 2010. 
[2] Amitava Bandyopadhyay, "A regulatory approach for e-waste management: a cross-national review of current practice and policy with an assessment and policy recommendation for the Indian perspective“, Int. J. of Environment and Waste Management, Vol. 2, No.1/2 pp. 139 - 186,2008.

[3] Population in The city of Misurata 2014, Municipility of Misurata Report, 2014.

[4] Joe Pickin, Paul Randell, “Australian National Waste Report 2016," Department of the Environment and Energy, june, 2017.

[5] Packaging Council of South Africa, "Design for Recycling for packaging and paper in South Africa," March, 2014.

[6] Mohamed Sawalem, Ibrahim Badi, Suleman Aljamel, Evaluation of Solid Wastes for Utilisation in Biogas Plant in Libya - a Case Study, IJESRT, November, 2015.

[7] Scott M. Kaufman, "ANALYSIS OF TECHNOLOGY AND INFRASTRUCTURE OF THE PAPER RECYCLING INDUSTRY IN NEW YORK CITY,” Columbia University. May, 2004.

[8] Hazel Fargher, Perry Franklin, Rachel Komara, "Increasing Paper and Cardboard Collection for Recycling in Denmark. May, 2015.

[9] http://www.tradingeconomics.com/libya/population-growth-annual-percent-wb-data.html 